\title{
Seroprevalence of Toxoplasma gondii assayed using Rapid Diagnostic Tests among Residents in Three Counties Adjacent to The Demilitarized Zone, Korea
}

\author{
Jeehi Jung ${ }^{1, \dagger}$, Jinyoung Lee, ${ }^{2, \dagger}$, Yoon Kyung Chang ${ }^{3}$, Seong Kyu Ahn², Seo Hye Park², Sung-Jong Hong ${ }^{4}$, \\ Jihoo Lee ${ }^{5}$, Chom-Kyu Chong ${ }^{5}$, Hye-Jin Ahn ${ }^{3}$, Ho-Woo Nam³, Tong-Soo Kim², Dongjae Kim,* \\ ${ }^{1}$ Department of Biomedicine Health Science, College of Medicine, The Catholic University of Korea, Seoul 06591, Korea; ${ }^{2}$ Department of Tropical \\ Medicine, Inha University School of Medicine, Incheon 22212, Korea; ${ }^{3}$ Department of Parasitology, College of Medicine, The Catholic University of \\ Korea, Seoul 06591, Korea; ${ }^{\circ}$ Department of Medical Environmental Biology, Chung-Ang University College of Medicine, Seoul 06974, Korea; \\ ${ }^{5}$ Genbody Inc., Cheonan 31116, Korea
}

\begin{abstract}
Toxoplasma gondii seroprevalence have been rapidly increasing in some parts of Korea. We analyzed prevalence of anti-Toxoplasma gondii antibodies, using a rapid diagnostic test (RDT), in the sera of 552 residents in Ganghwagun, 661 ones in Cheorwon-gun, and 305 ones in Goseong-gun, Korea in 2019. IgG/lgM RDT mounted with recombinant fragment of major surface antigen (SAG1), glutathione-S-transferase-linker-SAG1A, were applied to the sera. IgG seroprevalence was $28.1 \%$ in Ganghwa-gun, $19.5 \%$ in Cheorwon-gun and $35.7 \%$ in Goseong-gun. Odds ratios comparing Cheorwon vs Ganghwa was $0.63(P=0.001)$ and Goesong versus Ganghwa was $1.47(P=0.01)$ adjusting age and sex. Goseong had highest seroprevalence among the 3 counties both in crude rates and logistic regression. Although Cheorwon and Goseong are adjacent to the demilitarized zone (DMZ) in Korea, seroprevalence rate was much higher in Goseong. Further investigation on other DMZ-closed areas is necessary whether they have high prevalence rates compared to the other areas. T. gondii prevalence in Korea is still persists; proper health policy should be established.
\end{abstract}

Key words: Toxoplasmosis, sroprevalence, lgG, IgM, rapid diagnostic test

\section{INTRODUCTION}

Toxoplasma gondii is one of the common apicomplexan zoonotic protozoan parasites in humans and animals worldwide. Members of cat family are known as definite hosts of T. gondii, while humans and other war-blooded animals are intermediate hosts. T. gondii causes an infectious disease toxoplasmosis to its hosts. The hosts are infected to $T$. gondii by ingesting tissue cysts from undercooked meat, or by consuming food or water contaminated with oocytes. Another infection route is a placental T. gondii transmission from infected mother to her fetus; the toxoplasmosis that is infected by maternal transmission is called congenital toxoplasmosis [1-3]. Congenital toxoplasmosis may cause stillbirth or abortion; even after delivery, fetus may be born with serious damage such as neurological

- Received 5 October 2020, revised 14 January 2021, accepted 15 January 2021.

*Corresponding author (djkim@catholic.ac.kr)

†These authors contributed equally to this work.

(c) 2021, Korean Society for Parasitology and Tropical Medicine

This is an Open Access article distributed under the terms of the Creative Commons Attribution Non-Commercial License (https://creativecommons.org/licenses/by-nc/4.0) which permits unrestricted non-commercial use, distribution, and reproduction in any

medium, provided the original work is properly cited. disorder $[4,5]$. In T. gondii infection in adults, only small percentage shows clinical symptoms, and most cases are mild or asymptomatic. However, if the infection affects the central nervous system, it can lead to chronic condition. In patients with immune disorders, the infection can lead to toxoplasmic lymphadenitis, meningoencephalitis, or ocular toxoplasmosis [6-9].

In Korea, researches on T. gondii have been continued; increasing seroprevalence has been noticed in some areas in Korea [10-16]. Four-year follow-up study in Ganghwa and Cheorwon reported seroprevalence escalated during the study period, and the infection rate was higher in men than women [17]. Sukmo Island study also reported similar results that it observed rise in seroprevalence and higher prevalence in men than women [18]. Previous studies had shown that the seroprevalence is increasing, but there has been no study explored regional difference in seroprevalence. Also, previous studies made comparison using crude rates while conducting statistical analysis can give more evident support to the study findings. This study examines T. gondii seroprevalence in Ganghwa, Cheorwon and Goseong, which are geographically and socio- 
culturally similar areas, to clarify infection trends in Korea.

\section{MATERIALS AND METHODS}

\section{Ethics statement}

This study was performed under the regulation of the IRB Committee of Catholic University of Korea (MIRB-N20200609-004). This research adhered to the tenets of the Declaration of Helsinki. Written informed consent were provided to all participant, and no minors were enrolled to the study.

\section{Serum collection}

Sera of 552, 305, and 661 adult residents were collected in Ganghwa-gun, Cheorwon-gun and Goseong-gun, Korea respectively in 2019 (Table 1). Rapid diagnostic test (RDT) was performed on the samples to counter-check each other.
Rapid diagnostic test (RDT)

$\mathrm{RDT}$ is the currently most commonly used test for toxoplasmosis diagnosis, replacing ELISA which required a skilled technician and time-consuming procedure.

IgG/IgM RDT mounted with recombinant fragment of major surface antigen (SAG1), GST-linker-SAG1A [12,20], were applied to the sera mentioned above. Briefly, $10 \mu \mathrm{l}$ of serum was applied to the RDT sample hole and eluted with RDT buffer a few seconds later. Reacting bands were read after 15-20 minutes and its density was determined arbitrarily as $0,+,++$, and +++. Definite reactivity was determined as ++ (mid), while weaker and stronger reactivity compared to it was determined as + (weak) and +++ (strong). The final results were agreed upon by the 3 investigators.

Table 1. IgG/lgM tested Seroprevalence of T. gondii in Ganghwa, Cheorwon and Goseong by sex

\begin{tabular}{|c|c|c|c|c|c|c|c|c|}
\hline & \multicolumn{2}{|c|}{ Ganghwa $(n=552)$} & \multicolumn{2}{|c|}{ Cheorwon $(n=661)$} & \multicolumn{2}{|c|}{ Goseong $(n=305)$} & \multicolumn{2}{|c|}{ Overall $(\mathrm{N}=1,518)$} \\
\hline & n (\%) & $\mathrm{N}$ & n (\%) & $\mathrm{N}$ & $n(\%)$ & $\mathrm{N}$ & $n(\%)$ & $N$ \\
\hline \multicolumn{9}{|l|}{$\lg G$} \\
\hline Male & 75 (39.5) & 190 & $50(19.7)$ & 254 & 24 (29.6) & 81 & $149(28.4)$ & 525 \\
\hline Female & $80(22.1)$ & 362 & 79 (19.4) & 407 & 85 (37.9) & 224 & $244(24.6)$ & 993 \\
\hline Total & $155(28.1)$ & 552 & $129(19.5)$ & 661 & $109(35.7)$ & 305 & 393 (25.9) & 1,518 \\
\hline \multicolumn{9}{|l|}{$\lg M$} \\
\hline Male & $4(2.1)$ & 190 & $4(1.6)$ & 254 & $0(0.0)$ & 81 & $8(1.5)$ & 525 \\
\hline Female & $3(0.8)$ & 362 & $4(1.0)$ & 407 & $5(2.2)$ & 224 & $12(1.2)$ & 993 \\
\hline Total & $7(1.3)$ & 552 & $8(1.2)$ & 661 & $5(1.6)$ & 305 & $20(1.3)$ & 1,518 \\
\hline
\end{tabular}

Table 2. lgG/lgM tested Seroprevalence of T. gondii in Ganghwa, Cheorwon and Goseong by age groups

\begin{tabular}{|c|c|c|c|c|c|}
\hline & No. of Male & No. of Female & No. of lgG+ (\%) & No. of lgM+ (\%) & N \\
\hline \multicolumn{6}{|l|}{ Ganghwa } \\
\hline$\leq 59$ & 11 & 9 & $4(20.0)$ & $0(0.0)$ & 20 \\
\hline 60 to 69 & 28 & 62 & 31 (34.4) & $0(0.0)$ & 90 \\
\hline 70 to 79 & 71 & 148 & 57 (26.0) & $3(1.4)$ & 219 \\
\hline$\geq 80$ & 80 & 143 & 63 (28.3) & $4(1.8)$ & 223 \\
\hline Total & 190 & 362 & $155(28.1)$ & $7(1.3)$ & 552 \\
\hline \multicolumn{6}{|l|}{ Cheorwon } \\
\hline$\leq 59$ & 42 & 50 & 15 (16.3) & $3(3.3)$ & 92 \\
\hline 60 to 69 & 53 & 88 & $33(23.4)$ & $3(2.1)$ & 141 \\
\hline 70 to 79 & 95 & 156 & $43(17.1)$ & $0(0.0)$ & 251 \\
\hline$\geq 80$ & 64 & 113 & $38(21.5)$ & $2(1.1)$ & 177 \\
\hline Total & 254 & 407 & $129(19.5)$ & $8(1.2)$ & 661 \\
\hline \multicolumn{6}{|l|}{ Goseong } \\
\hline$\leq 59$ & 7 & 5 & $1(8.3)$ & $0(0.0)$ & 12 \\
\hline 60 to 69 & 8 & 33 & $14(34.1)$ & $0(0.0)$ & 41 \\
\hline 70 to 79 & 35 & 92 & $53(41.7)$ & $5(3.9)$ & 127 \\
\hline$\geq 80$ & 31 & 94 & 41 (32.8) & $0(0.0)$ & 125 \\
\hline Total & 81 & 224 & $109(35.7)$ & $5(1.6)$ & 305 \\
\hline
\end{tabular}




\section{Statistical Analysis}

Logistic Regression was used to estimate adjusted odds ratios. Each odds ratio represents an estimated effect of a variable adjusting other covariates that were included in the model. Results were considered statistically significant at a significant level of 0.05 . All statistical analyses were performed with SAS 9.4.

\section{RESULTS}

\section{Crude Rates}

The study enrolled participants from 3 cities in Korea: Ganghwa, Cheorwon and Goseong. 1,543 participants underwent the RDT1(IgG) and RDT2(IgM) tests. This study enrolled 1,543 participants from 3 counties. Of them, 25 participants were excluded from the analysis due to missing data, leaving 1,518 for statistical analysis.

Of the 1,518 overall population, $25.9 \%$ of participants were IgG positive while only $1.3 \%$ were IgM positive (Table 1 ). 525 male and 993 female participants were enrolled in this study.
$28.4 \%$ of men and $24.6 \%$ of women were $\operatorname{IgG}$ positive (Table 1 ). $28.1 \%, 19.5 \%$ and $35.7 \%$ were IgG positive from Ganghwa, Cheorwon and Goseong respectively. In terms of age groups, 124 were aged less than or equal to 59, 272 were 60 to 69,597 were 70 to 79 and 525 were older than $80.16 .1 \%, 28.7 \%$, $25.6 \%$, and $27.1 \%$ were IgG positive from age groups less than or equal to 59,60 to 69,70 to 79 , and 80 plus respectively. The difference among the age groups was not statistically significant; yet, it was very close to 0.05 (Fig. 1). IgM positive rates were from minimum $1.1 \%$ to maximum $2.4 \%$. Since IgM positive rate is very low, it was hard to detect statistical difference with current sample size.

Among the 1,518 participants, 552 were from Ganghwa; 661 and 305 were from Cheorwon and Goseong respectively. In Ganghwa, 190 men and 362 women were surveyed, 20 were aged less than or equal to 59, 90 were aged between 60 and 69, 219 were between 70 and 79 and 223 were 80 or older. IgG seroprevalence was $39.5 \%$ in men and $22.1 \%$ in women. In Cheorwon, 254 men and 407 women were surveyed; among them, 92 were aged 59 or under, 141 were 60 to 69 ,

Table 3. Odds ratios of lgG/lgM tested T. gondii event in multivariable logistic regression models

\begin{tabular}{|c|c|c|c|c|c|c|c|}
\hline \multirow{2}{*}{ Variable } & \multirow{2}{*}{ Comparison } & \multicolumn{3}{|c|}{$\operatorname{lgG}($ model 1) } & \multicolumn{3}{|c|}{ lgM (model 2) } \\
\hline & & $\mathrm{OR}^{*}$ & $95 \% \mathrm{Cl}$ & $P$-value & $\mathrm{OR}^{\star}$ & $95 \% \mathrm{Cl}$ & $P$-value \\
\hline \multirow[t]{2}{*}{ Region } & Cheorwon vs Ganghwa & 0.63 & $0.48-0.83$ & 0.001 & 0.85 & $0.30-2.42$ & 0.76 \\
\hline & Goseong vs Ganghwa & 1.47 & 1.09-1.99 & 0.01 & 1.31 & $0.41-4.18$ & 0.65 \\
\hline Sex & Male vs Female & 1.34 & $1.05-1.71$ & 0.02 & 1.24 & $0.50-3.09$ & 0.64 \\
\hline \multirow[t]{5}{*}{ Age group } & $60-69$ vs $\leq 59$ & 1.96 & $1.13-3.42$ & 0.02 & 0.44 & $0.09-2.27$ & 0.33 \\
\hline & $\geq 80$ vs $\leq 59$ & 1.60 & $0.94-2.72$ & 0.08 & 0.43 & $0.10-1.86$ & 0.26 \\
\hline & 70-79 vs 60-69 & 0.79 & $0.57-1.10$ & 0.16 & 1.17 & $0.31-4.48$ & 0.82 \\
\hline & $\geq 80$ vs 60-69 & 0.82 & $0.59-1.14$ & 0.23 & 0.98 & 0.24-3.99 & 0.98 \\
\hline & $\geq 80$ vs 70-79 & 1.03 & $0.79-1.35$ & 0.84 & 0.84 & $0.29-2.43$ & 0.74 \\
\hline
\end{tabular}

${ }^{*}$ Adjusted Odds Ratio.
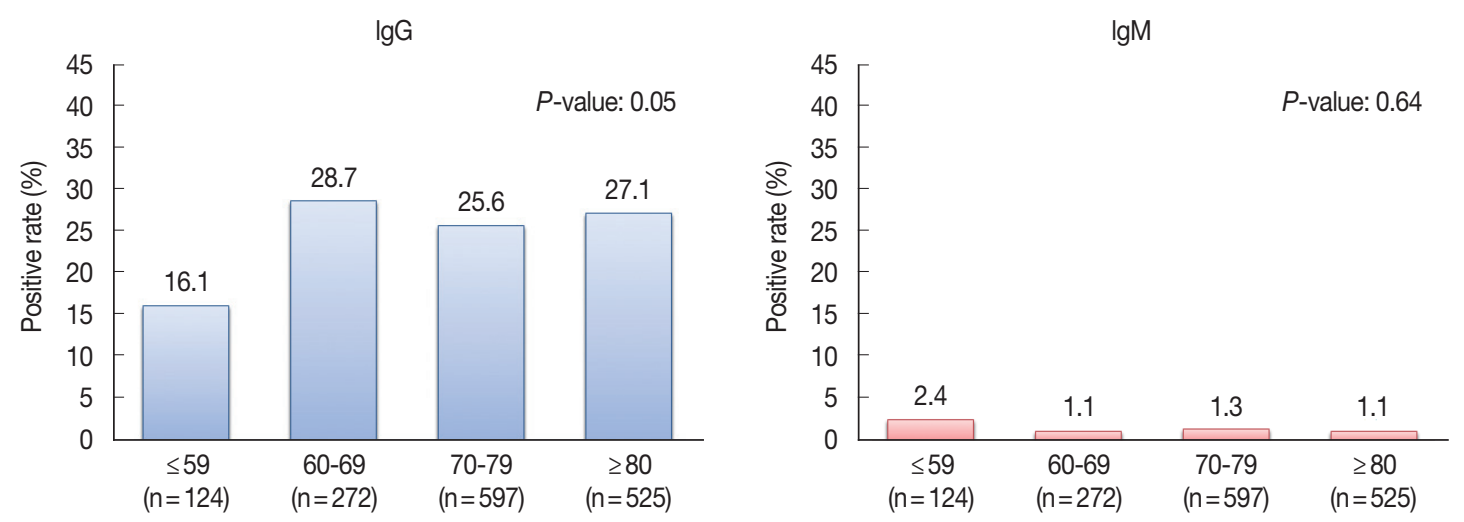

Fig. 1. lgG/lgM tested seroprevalence rate of $T$. gondii by age groups. Chi-square test was performed for both $\lg G$ and $\lg M$. 
251 were 70 to 79 and 177 were 80 or older. IgG seroprevalence in Cherowon was $19.7 \%$ in men and $19.4 \%$ in women. 81 men and 224 women were surveyed in Goseong, of which 12 were aged 59 or younger, 41 were aged 60 to 69, 127 were aged 70 to 79 and 125 were aged 80 or older. IgG seroprevalence was $29.6 \%$ in men and $37.9 \%$ in women (Tables 1, 2). Age group less than or equal to 59 years old showed lower incidence rate than other age groups, but no apparent increasing trend was shown as age increases (Table 2). In case of IgM seroprevalence, it appeared from $0 \%$ to $3.9 \%$; the numbers of cases were very small (Tables 1,2 ). In all 3 study areas, men had higher seroprevalence than women, and more than 50\% of the population were elders over the age of 70. Ganghwa has the highest male IgG seroprevalence rate (39.5\%), while Goseong has the highest female prevalence (37.9\%).

\section{Logistic Regression}

Odds can be defined as a chance or likelihood of a certain event or a disease occurs. In a logistic regression model, an odds ratio (OR) represents a level of association between a risk factor and a disease adjusting other variables that were included in the model. If OR equals to 1 , it means that there's no association between the risk factor and the disease. When OR is greater than 1, the risk group has higher odds of the disease occurrence than the non-risk group. Similarly, OR less than 1 can be interpreted that the risk group has lower odds of the disease occurrence than the non-risk group. In Table 3, if we suppose Choerwon as a risk group and Ganghwa as a comparison group (non-risk group), then odds of IgG T. gondii occurrence in Choerwon is 0.63 times lower than that in Ganghwa (OR 0.63, 95\% CI 0.48-0.83, P-value 0.001) adjusting age and sex. Using the same interpretation, OR of Goseong versus Ganghwa was 1.47 (95\% CI 1.09-1.99, P-value 0.01), and we can conclude that odds of T. gondii event in Goseong is 1.47 times higher than that in Ganghwa. Since P-values of both ORs were less than the statistically significant level of 0.05 , seroprevalence of $T$. gondii in Goseong is statistically higher than that in Ganghwa while T. gondii odds in Cheorwon is statistically lower than that in Ganghwa. Goseong not only has the highest prevalence rate in Table 1 but also has the highest odds in the statistical analysis. Yet, there was no regional difference found with the IgM model. In terms of gender difference in $T$. gondii infection, men have statistically higher odds of $T$. gondii by IgG compared to women (OR 1.34, 95\% CI 1.05-1.71, Pvalue 0.02 ) adjusting region and age; no difference found with
IgM. Age group of 60 to 69 had higher odds than the age group of 59 or younger (OR 1.96, 95\% CI 1.13-3.42, P-value 0.02 ) in IgG, but other age group comparisons were not statistically significant. There was no evident age effect on $T$. gondii prevalence in both IgG and IgM. The IgM test showed no difference in T. gondii seroprevalence for sex, region and age, while IgG method had statistically significant regional and gender effect on $T$. gondii prevalence.

\section{DISCUSSION}

Soh et al. [21] first reported T. gondii seroprevalence of 5.6\% among 373 participants in 1960s using toxoplasmin skin test. Since then, various serological methods, indirect fluorescent antibody test (IFAT), indirect latex agglutination test and ELI$\mathrm{SA}$, were used. However, these methods were time-consuming and expensive. In this study, Rapid diagnostic test (RDT) using recombinant protein as an antigen was performed which could save time and expenses.

The prevalence of $T$. gondii in Korea has remained relatively low since the first survey in 1960 until 2010. The 2010 study in Ganghwa and Cheorwon showed a sharp increase in prevalence. Such surge could be related to environmental and socioeconomic changes in Korea. As the Korea economy has grown rapidly, interest in health and environmental issues naturally began to grow. The use of pesticides decreased due to popularity of organic foods, which possibly could lead to increase in exposure to T. gondii $[22,23]$.

Geographical factor also could be contributed to the increase in seroprevalence. Ganghwa, Cheorwon and Goseong are $\mathrm{DMZ}$ areas which have the zones that ban civilian access. Due to such characteristic, higher number of wild animals inhabit in these areas compared to other parts of Korea, and the wild animals are the potential reservoir hosts of $T$. gondii.

According to studies conducted in Ganghwa and Cheorwon from 2010 to 2013, men's prevalence in both regions was 1.5 times higher than that of women $[17,18]$. Previous studies have speculated that this phenomenon is due to the fact that men are more active in socioeconomic activities than women in rural areas. Also, some elders in rural, especially in men, believe that consuming animal's intestines raw is good for their health. In this 2019 study, men had a higher prevalence rate in Ganghwa, but women had a higher prevalence rate in Goseong. Yet, men had statistically significantly higher odds than women adjusting region and age in the logistic regression 
model.

Another reason for the surge in the T. gondii seroprevalence is the increase in meat consumption. Consuming undercooked meat that consists T. gondii as cyst can cause the infection. The annual meat consumption in Korea increased by more than 20 kilograms from 31.9 kilograms per person in 2000 to 53.9 kilograms per person in 2018. And, meat imports increased $114 \%$ from 394,000 tons in 2000 to 845,000 tons in 2017 to meet the demand. T. gondii is widespread around the world, but there is a risk of infection, especially if meat is imported from countries such as Argentina and Brazil, which have high prevalence rates. Furthermore, no quarantine is currently being carried out on $T$. gondii in imported meat.

Another cause of the spike in prevalence can be attributed to the increase in pet popularity. Pet cats are known to be less likely to be a source of infection for T. gondii; yet, they can become infectious agents if they contact with infected wild animals. Pets in rural areas have more chance to contact with wild animals, which can be thought of as one of reasons for the high seroprevalence rate in rural areas. As cats become popular as pets, the number of abandoned cats also increases which led to the increase in the number of feral cats. The T. gondii infection rate was $38.9 \%$ in 72 feral cats in 9 districts of Seoul in 2010. In 2011, 456 wild cats in 17 districts in Seoul were tested and infection rate was about $16 \%$.

The first thing to note in this study is the decrease in prevalence in Cheorwon and Ganghwa. The prevalence rate in Cheorwon was on the rise from $19.3 \%$ in 2010 to $26.8 \%$ in 2013; however, in 2019, the rate dropped to $19.5 \%$ which is similar to the level in 2010. In the case of Ganghwa, the rate increased steeply for 3 consecutive years from $21.7 \%$ in 2010 to $33.1 \%$ in 2013 but decreased to $28.1 \%$ in 2019 . The most likely cause of this decrease in prevalence is the change in age groups. The prevalence rate was the highest among those aged 80 or older in 2013; as time goes by, the death of those elders in 2013 could bring a decrease in the overall prevalence rate in 2019. Considering that the prevalence rates in the 60s are not significantly different comparing 2013 and 2019, except for the effect of reducing the prevalence rate caused by deaths in elders, the prevalence rate is on a stabilized trend. For the low prevalence rate in 50s, we should consider that the investigated areas were rural and the number of aged 59 or younger were only 124 combining all 3 areas which is very low number compared to other age groups.

Unlike Ganghwa and Cheorwon, Goseong was first investi- gated in this study and had a high prevalence rate of $35.7 \%$. Goseong's prevalence rate is higher than the highest rate of 33.1\% in 2013 Ganghwa. In addition, statistical analysis also showed Goseong had higher odds than in other regions. Goseong was expected to show a similar prevalence rate as Cheorwon since both has similar geographical characteristics; however, the prevalence rate in Goseong was much higher than that of Cheorwon. Therefore, further investigation is needed whether other DMZ areas also have such high prevalence rate.

Toxoplasmosis is widespread around the world, but it has been neglected in health policies as the symptoms are often mild or asymptomatic. Since T. gondii prevalence rate before 2010 in Korea was estimated around 10\%, which was much lower than the global level of 25 to $30 \%$, it was not considered as an important issue. However, the prevalence rate of Ganghwa, Cheorwon and Goseong in 2019 is $25.9 \%$ similar to the global level. Because the investigated areas are rural regions, the estimated prevalence is likely to be higher than that of other regions in Korea, but it is hard to say that this infection problem is only limited to rural areas. Toxoplasmosis can cause serious complications such as encephalitis and ocular toxoplasmosis when reactivated in immunodeficiency. Infection in a pregnant woman can cause a maternal transmission, leaving a neurological after effect. These clinical significances have been ignored, but with the growing elderly population, the need for related research will grow even more. As this study confirmed that the high prevalence of $T$. gondii continues in some parts of Korea, nationwide prevalence investigations and appropriate health policies are needed.

\section{ACKNOWLEDGMENT}

This study was supported by a research grant from the Korea Association of Health Promotion (No. 2015-01) to HW Nam and the National Research Foundation of Korea grant funded by the Korean government (NRF-2017M3A9B8069530) to TS Kim.

\section{CONFLICT OF INTEREST}

The authors declare no conflict of interest related to this study. 


\section{REFERENCES}

1. Black MW, Boothroyd JC. Lytic cycle of Toxoplasma gondii. Microbiol Mol Biol Rev 2000; 64: 607-623. https://doi.org/10.1128/ mmbr.64.3.607-623.2000

2. Furtado JM, Smith JR, Belfort R Jr, Gattey D, Winthrop KL. Toxoplasmosis: a global threat. J Glob Infect Dis 2011; 3: 281-284. https://doi.org/10.4103/0974-777X.83536

3. Tenter AM, Heckeroth AR, Weiss LM. Toxoplasma gondii: from animals to humans. Int J Parasitol 2000; 30: 1217-1258. https:// doi.org/10.1016/s0020-7519(00)00124-7

4. Montoya JG, Remington JS. Management of Toxoplasma gondii infection during pregnancy. Clin Infect Dis 2008; 47: 554-566. https://doi.org/10.1086/590149

5. Song KJ, Shin JC, Shin HJ, Nam HW. Seroprevalence of toxoplasmosis in Korean pregnant women. Korean J Parasitol 2005; 43: 69-71. https://doi.org/10.3347/kjp.2005.43.2.69

6. Weiss LM, Dubey JP. Toxoplasmosis: A history of clinical observations. Int J Parasitol 2009; 39: 895-901. https://doi.org/10.1016/ j.ijpara.2009.02.004

7. Choi WY, Nam HW, Kwak NH, Huh W, Kim YR, Kang MW, Cho SY, Dubey JP. Foodborne outbreaks of human toxoplasmosis. J Infect Dis 1997; 175: 1280-1282. https://doi.org/10.1086/593702

8. Kim MH, Choi YK, Park YK, Nam HW. A toxoplasmic uveitis case of a 60-year-old male in Korea. Korean J Parasitol 2000; 38 : 29-31. 10.3347/kjp.2000.38.1.29

9. Park YH, Han JH, Nam HW. Clinical features of ocular toxoplasmosis in Korean patients. Korean J Parasitol 2011; 49: 167-171. https://doi.org/10.3347/kjp.2011.49.2.167

10. Choi WY, Nam HW, Youn JH, Kim WS, Kim WK. Toxoplasma antibody titers by indirect latex agglutination test in patients of Kangnam St. Mary's Hospital and Cheju Medical Center. Korean J Parasitol 1989; 27: 171-175. https://doi.org/10.3347/kjp.1989.27.3.171

11. Choi WY, Nam HW, Youn JH, Kim DJ, Kong Y, Kang SY, Cho SY. Detection of antibodies in serum and cerebrospinal fluid to Toxoplasma gondii by indirect latex agglutination test and enzyme-linked immunosorbent assay. Korean J Parasitol 1992; 30: 83-90. https://doi.org/10.3347/kjp.1992.30.2.83

12. Hong SJ, Chong CK, Lee K, Kim TS, Hong YP, Ahn HJ, Kim HY, Ko AR, Kim YJ, Nam HW. Maintained seroprevalence of toxoplasmosis among the residents of Jeju island, Korea. Korean J Parasitol 2011; 49: 309-311. https://doi.org/10.3347/kjp.2011.49.3.309

13. Yang HJ, Jin KN, Park YK, Hong SC, Bae JM, Lee SH, Choi HS, Hwang HS, Chung YB, Lee NS, Nam HW. Seroprevalence of toxoplasmosis in the residents of Cheju island, Korea. Korean J Parasi- tol 2000; 38: 91-93. https://doi.org/10.3347/kjp.2000.38.2.91

14. Ahn HJ, Cho PY, Ahn SK, Kim TS, Chong CK, Hong SJ, Cha SH, Nam HW. Seroprevalence of toxoplasmosis in the residents of Cheorwon-gun, Gangwon-do, Korea. Korean J Parasitol 2012; 50: 225-227. https://doi.org/10.3347/kjp.2012.50.3.225

15. Yang Z, Cho PY, Ahn SK, Ahn HJ, Kim TS, Chong CK, Hong SJ, Cha SH, Nam HW. A surge in the seroprevalence of toxoplasmosis among the residents of islands in Gangwha-gun, Incheon, Korea. Korean J Parasitol 2012; 50: 191-197. https://doi.org/10.3347/ kjp.2012.50.3.191

16. Kim YH, Lee JH, Ahn SK, Kim TS, Hong SJ, Chong CK, Ahn HJ, Nam HW. Seroprevalence of Toxoplasmosis with ELISA and Rapid Diagnostic Test among Residents in Gyodong-do, Inchon city, Korea: A Four-Year Follow-up. Korean J Parasitol 2017; 55.3: 247-254. https://doi.org/10.3347/kjp.2017.55.3.247

17. Kim YH, Lee JH, Kim YE, Ahn SK, Kim TS, Hong SJ, Chong CK, Ahn HJ, Nam HW. Seroprevalence of Toxoplasmosis Detected by RDT in Residents near the DMZ (demilitarized zone) of Cheorwon-gun, Gangwon-do, Korea. Korean J Parasitol 2017; 55.4: 385-389. https://doi.org/10.3347/kjp.2017.55.4.385

18. Kim YH, Lee JH, Ahn SK, Kim TS, Hong SJ, Chong CK, Ahn HJ, Nam HW. High seroprevalence of toxoplasmosis detected by RDT among the residents of Seokmo-do (Island) in GanghwaGun, Incheon City, Korea. Korean J Parasitol 2017; 55.1: 9-13. https://doi.org/10.3347/kjp.2017.55.1.9

19. Sohn WM, Nam HW. Western blot analysis of stray cat sera against Toxoplasma gondii and the diagnostic availability of monoclonal antibodies in sandwich-ELISA. Korean J Parasitol 1999; 37: 249-256. https://doi.org/10.3347/kjp.1999.37.4.249

20. Song KJ, Yang Z, Chong CK, Kim JS, Lee KC, Kim TS, Nam HW. A rapid diagnostic test for toxoplasmosis using recombinant antigenic N-terminal half of SAG1 linked with intrinsically unstructured domain of gra2 protein. Korean J Parasitol 2013; 51: 503-510. https://doi.org/10.3347/kjp.2013.51.5.503

21. Soh CT, Lee SJ, Ahn YK. Latent infection by Toxoplasma gondii in Korea. Yonsei Med J 1960; 1: 52-54. https://doi.org/10.3349/ ymj.1960.1.1.52

22. Dubey JP, Hill DE, Rozeboom DW, Rajendran C, Choudhary S, Ferreira LR, Kwok OC, Su C. High prevalence and genotypes of Toxoplasma gondii isolated from organic pigs in northern USA. Vet Parasitol 2012; 188: 14-18. https://doi.org/10.1016/j.vetpar.2012.03.008

23. Meerburg BG, De Craeye S, Dierick K, Kijlstra A. Neospora caninum and Toxoplasma gondii in brain tissue of feral rodents and insectivores caught on farms in the Netherlands. Vet Parasitol 2012; 184: 317-320. https://doi.org/10.1016/j.vetpar.2011.09.001 